\title{
P107: Moving from standard alcoholic hand rub dispensers to a wireless LAN based system with continuous monitoring: evaluation after one year
}

\author{
B Batzer ${ }^{1 *}$, S Scheithauer ${ }^{1,2}$, C Pino Molina ${ }^{3}$, A Widmer ${ }^{1}$ \\ From 2nd International Conference on Prevention and Infection Control (ICPIC 2013) \\ Geneva, Switzerland. 25-28 June 2013
}

\section{Introduction}

Improving hand hygiene compliance is a cornerstone of any infection control program. Manual observation temporarily improves adherence, but is time-consuming and rarely feasible long term. Electronic counting dispensers allowing real time assessment and feedback of hand hygiene events (HHE) are an effective tool for monitoring compliance $24 / 7 / 365$.

\section{Objectives}

The aim of the study was to evaluate utility and acceptance, and to identify possible shortcomings of the Ingoman Weco (Ophardt Hygienetechnik, Issum; Germany).

\section{Methods}

In January 2012 all dispensers $(\mathrm{N}=63)$ at a 13 bed hematology ward with approximately 100 transplantations/year were exchanged by Ingo-man Weco. The energy for the data transfer derived from pulling the lever of the dispenser, no battery is necessary or power lines. A built-in wireless recording equipment sending the information to a server. HHE event is defined as two activities maximum 2 seconds apart. All HHEs were continuously recorded from 03-09/12 and could be analyzed dispenser-, day-, shift-, localization-specifically. At the hematology ward about 280 patients referring to 3600 patient-days were cared for annually.

\section{Results}

Overall, 3 dispenser were placed in the each patient room, 13 in the hallways, and 11 at nursing stations and others locations. The new devices were well accepted without handling problems. During the pilot phase, 13 dispensers with very low activities were identified and subsequently relocated.

During the 7-month lasting study, a total of 123'171 HHE could be documented. The majority $\left(65^{\prime} 683\right.$ / 123 '171; 53\%) occurred at dispensers located at patient's door entry. Only $8 \%(10276 / 123171)$ referred to dispensers located in the patient rooms.

Four $(6 \%)$ dispensers went broken. Two of them were located at the laminar air flow benches, the damage was probably driven by the UV exposition.

\section{Conclusion}

The Ingo-man Weco is an easy to install and ready to use device, requiring no battery or power installation, that offers $24 / 7 / 365$ data on hand hygiene activities. It allows improving dispensers location, and continuous monitoring.

\section{Disclosure of interest}

None declared.

\section{Author details}

'Infection Control, Unispital Basel, Basel, Switzerland. ${ }^{2}$ Infection Control \& Infectious Diseases, University Hospital Aachen; RWTH Aachen, Aachen, Germany. ${ }^{3}$ Hematology, Unispital Basel, Basel, Switzerland.

Published: 20 June 2013

doi:10.1186/2047-2994-2-S1-P107

Cite this article as: Batzer et al:: P107: Moving from standard alcoholic hand rub dispensers to a wireless LAN based system with continuous monitoring: evaluation after one year. Antimicrobial Resistance and Infection Control 2013 2(Suppl 1):P107.

Infection Control, Unispital Basel, Basel, Switzerland

Full list of author information is available at the end of the article

(c) 2013 Batzer et al; licensee BioMed Central Ltd. This is an Open Access article distributed under the terms of the Creative Commons 